\title{
National Cancer Institute Cancer Centers Program
}

National Cancer Institute

\section{Source}

National Cancer Institute. National Cancer Institute Cancer Centers Program. NCI

Thesaurus. Code C39466.

The $\mathrm{NCl}$ Cancer Centers Program comprises more than $50 \mathrm{NCl}$-designated cancer centers eng aged in multidisciplinary research to reduce cancer incidence, morbidity and mortality. Through Cancer Center Support grants, this program supports three types of centers: Comprehensive Cancer Centers, Clinical Cancer Centers, and Cancer Centers. It was the National Cancer Act of 1971 that strengthened the program by authorizing the establishment of 15 new cancer centers and the continued support for existing ones. 